\title{
Development and Validation of a Rapid and Sensitive Stability-indicating RP-HPLC Method for Resveratrol Quantification in Pharmaceutical Formulation
}

\author{
Shivaprasad Gadag, Reema Narayan, Chetan Hasmukh Mehta, Akhil Suresh, Usha Yogendra Nayak*
}

Department of Pharmaceutics, Manipal College of Pharmaceutical Sciences, Manipal Academy of Higher Education,

Manipal - 576104, Karnataka, INDIA.

\begin{abstract}
Background: Trans-resveratrol (RVT) is a phytoconstituent belonging to the family of polyphenols, extensively studied for its numerous health benefits. However, its susceptibility for photolytic, oxidative, and hydrolytic degradation, hinders the quantification of RVT present in different formulations. In the present study, a novel, precise, simple, reproducible, accurate, and stability indicating reversed-phase high performance liquid chromatography (RP-HPLC) method was developed and validated using quality by design for the quantification of RVT in pharmaceutical formulation. Force degradation studies were carried out, and the intrinsic stability of RVT was assessed using the proposed method. Materials and Methods: Chromatographic separation of RVT was obtained on Phenomenex Kinetex $\mathrm{C}_{18}(250 \times 4.6 \mathrm{~mm}, 5 \mu, 100 \AA)$ stationary phase with isocratic elution using $0.2 \% \mathrm{v} / \mathrm{v}$ trifluoroacetic acid (TFA) in HPLC grade water and acetonitrile $(\mathrm{ACN})$ in the ratio $75: 25 \% \mathrm{v} / \mathrm{v}$. A flow rate of $1.0 \mathrm{ml} / \mathrm{min}$ was maintained for pumping the mobile phase, and the eluent was detected at a wavelength of 306 $\mathrm{nm}$. Results: RVT was found to elute at a retention time $\left(t_{R}\right)$ of $6.96 \pm 0.08 \mathrm{~min}$. The method was linear in the range of $0.1 \mu \mathrm{g} / \mathrm{ml}$ to $2.0 \mu \mathrm{g} / \mathrm{ml}$ concentration with correlation coefficient 0.9998 . The \% recovery was found to be 100.16 to $101.73, \%$ RSD of six replicate standards was found to be 0.58 . The excipients present in the formulation did not show any interference in the analysis of RVT, indicating the specificity of the developed method. Conclusion: The proposed method can be applied for the quantification of RVT in a pharmaceutical formulation, dietary supplements, and bulk drug.
\end{abstract}

Key words: Trans-resveratrol, RP-HPLC, Method validation, Force degradation, Specificity.

\section{INTRODUCTION}

Trans-resveratrol (RVT) is a phytoconstituent present abundantly in grapes, berries (blueberries, raspberries, mulberries) and peanuts. ${ }^{1}$ RVT is an extensively studied molecule due to its various health benefits by its action on different targets. It is widely explored for its anti-tumor, anti-acne, antidiabetic, anti-inflammatory, photoprotective, anti-obesity and neuroprotective property. ${ }^{2}$ The chemotherapeutic benefits of RVT studied on cancer cell lines MCF-7 and T47D and in 1-methyl-1-nitrosourea (MNU) induced breast cancer in rats have demonstrated the chemotherapeutic potentials of $\mathrm{RVT}^{3-5}$ It is approved as a nutraceutical by
USFDA, however an increase in the clinical trials of RVT in different fields such as neurology, oncology and obesity management, thus gaining attention of Pharmaceutical industries for its translation use. ${ }^{6}$ RVT is an off-white powder with $\log P$ value 2.57 , pKa 8.49 having water solubility $0.0688 \mathrm{mg} / \mathrm{mL}$ (www.drugbank.ca).

For the quantification of RVT, several analytical methods like gas chromatography with mass spectrometry detector (GC-MS), ${ }^{7}$ HPLC with mass spectrometry detector (HPLC-MS) methods ${ }^{8-10}$ have been reported. An advantage of HPLC method over
Submission Date: 23-09-2020; Revision Date: 14-05-2021; Accepted Date: 23-09-2021

DOI: 10.5530/ijper.55.3s.190 Correspondence: Dr. Usha Yogendra Nayak, Department of Pharmaceutics, Manipal College of Pharmaceutical Sciences, Manipal Academy of Higher Education, Manipal-576104, Karnataka, INDIA.

Phone: +91-0820-2922482, Email - usha.nayak@manipal.edu

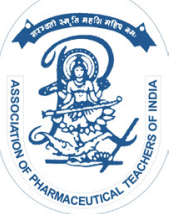

www.ijper.org 
other methods is the detection of resveratrol and its metabolites in lower concentration. ${ }^{11-15}$ Nour $\mathrm{V}$ et al. have developed HPLC method for the quantification of trans- and cis-resveratrol present in the red wine, by using $\mathrm{C}_{18}$ column with gradient elution with $2 \%$ acetic acid and acetonitrile. ${ }^{16}$ Shah $\mathrm{A}$ and co-workers have developed and validated a HPLC method for the quantification of resveratrol in the formulation using $\mathrm{pH} 4.5$ ammonium acetate $(25 \mathrm{mM})$ and acetonitrile as mobile phase in the ratio of $45: 55 .{ }^{17}$ RVT belongs to the family of polyphenols and like other polyphenols, RVT is also sensitive for the oxidative and hydrolytic degradation. ${ }^{18,19}$ The trans isomer of RVT is converted into less active cis-isomer in presence of UV light. ${ }^{16,20}$ So, it is very essential to develop quantification method which will indicate the stability of the RVT.

Reported HPLC methods for RVT quantification, has the drawback such as the use of high organic solvent and complex mobile phase composition. ${ }^{21,22}$ Till date, no literatures exist where stability indicating assay method have been developed for the detection of RVT in the presence of degradants. The present work deals with the development of a novel, precise, simple and accurate less expensive method for the quantification of RVT in the transdermal patch formulation and validation of the same according to ICH Q2(R1) guidelines. ${ }^{23}$ The preparation of the mobile phase in this study is simple, as it does not involve the addition of buffer salts and no $\mathrm{pH}$ adjustment is necessary.

\section{MATERIALS AND METHODS}

\section{Instrumentation and reagents}

RVT was procured from TCI Chemicals (India) Pvt. Ltd. (Chennai, India). Potassium di-hydrogen orthophosphate, ammonium acetate, sodium hydroxide $(\mathrm{NaOH})$, glacial acetic acid, trifluoroacetic acid (TFA), ortho phosphoric acid (OPA), triethylamine (TEA) and acetonitrile (ACN) were purchased from Merck Ltd. (Mumbai, India). Methanol was procured from Finar Ltd. (Ahmedabad, India). Hydrogen peroxide $\left(\mathrm{H}_{2} \mathrm{O}_{2}\right)$ $30 \%$ and hydrochloric acid $(\mathrm{HCl})$, were purchased from Loba Chemie (Mumbai, India) and Himedia Labs (Mumbai, India), respectively. HPLC grade water was produced in the lab using a Millipore Direct-Q3 system (Millipore (India) Pvt. Ltd., Bangalore).

Shimadzu LC-2010 CHT (Shimadzu Corporation, Kyoto, Japan) make, with low-pressure quaternary pumps, SPD-M20A prominence photodiode array detector (PDA), ultraviolet (UV) detector with dual wavelength, degasser unit, high throughput autosampler and column oven. LC solution 5.57 software was used for data acquisition, controlling the system and processing of chromatograms.

The samples, standard and chemicals, were weighed using an analytical balance (Sartorius AG, Germany). Mobile phase solution was filtered using $0.22 \mu \mathrm{m}$ membrane filter. The mobile phase was degassed using an ultrasonic bath (GT Sonic, Servewell Instruments Pvt. Ltd., Bangalore, India) and $\mathrm{pH}$ meter (Eutech Instruments $\mathrm{pH} 510$ ) was used to measure the $\mathrm{pH}$ of the mobile phase.

\section{Chromatographic conditions}

The best separation of RVT was obtained by using Phenomenex Kinetex $\mathrm{C}_{18}(250 \times 4.6 \mathrm{~mm}, 5 \mu, 100 \AA)$ as the stationary phase with isocratic elution using $0.2 \%$ $\mathrm{v} / \mathrm{v}$ TFA in water and ACN in the ratio $75: 25 \% \mathrm{v} / \mathrm{v}$. $1.0 \mathrm{ml} / \mathrm{min}$ flow rate was set with a run time of $12 \mathrm{~min}$ using $10 \mu \mathrm{l}$ as injection volume. Column oven temperature and autosampler temperature were set at $25^{\circ} \mathrm{C}$ and $4^{\circ} \mathrm{C}$ respectively and $306 \mathrm{~nm}$ was kept as detection wavelength.

\section{Preparation of standard solutions and formulation samples}

\section{Preparation of working standard}

$10.0 \mathrm{mg}$ of accurately weighed RVT active pharmaceutical ingredient (API) was diluted with diluent $(50 \% \mathrm{ACN}$ in water) to obtain a solution of $1.0 \mu \mathrm{g} / \mathrm{ml}$ concentration.

\section{Preparation of formulation samples}

$1 \mathrm{~cm}^{2}$ of patch formulation was cut, extracted with diluent by sonicating for $15 \mathrm{~min}$ and further diluted with diluent to get the same concentration as that of standard solution (i.e., $1.0 \mu \mathrm{g} / \mathrm{ml}$ ).

\section{Method optimization}

For method development, Phenomenex Jupiter $\mathrm{C}_{4}$ column $(250 \times 4.6 \mathrm{~mm}, 5 \mu)$ and $\mathrm{C}_{18}$ column having dimension $250 \times 4.6 \mathrm{~mm}, 5 \mu$ with different column chemistry such as Phenomenex Luna and Phenomenex Kinetex were tried. The effect of different mobile phase such as phosphate buffer $\mathrm{pH} 6.8$, acetate buffer $\mathrm{pH} 4.5$, $0.1 \%$ OPA in water and $0.2 \%$ TFA in water along with the varying ratio of organic solvents such as acetonitrile/ methanol were studied.

To arrive at the optimum method, parameters namely $\%$ RSD (percentage relative standard deviation) of six replicates of the standard solution, tailing factor, theoretical plate count were calculated as a part of assessing the suitability of the system. During method development, attention was given to ensure short runtime, low organic solvent consumption, optimum 
theoretical plate count $(>2000)$ and peak asymmetry near to 1.0 .

\section{Method validation}

The developed HPLC method was validated for the following parameters as per ICH Q2(R1) guidelines. ${ }^{24}$

\section{Specificity}

Interference from solvent and placebo was evaluated at the retention time $\left(t_{R}\right)$ of the main peak of RVT by injecting diluent, placebo, RVT standard and RVT formulation sample solution into HPLC.

\section{Force degradation}

Force degradation was performed to assess the purity of RVT peak as observed on the PDA detector.

\section{Thermal degradation}

RVT patch formulation was exposed to $105^{\circ} \mathrm{C}$ for 24 $\mathrm{h}$ and sample solution $(1.0 \mu \mathrm{g} / \mathrm{ml})$ was prepared using diluent (50\% ACN in HPLC grade water)

\section{Photolytic degradation}

RVT patch formulation was exposed to sunlight for $24 \mathrm{~h}$ and sample solution $(1.0 \mu \mathrm{g} / \mathrm{ml})$ was prepared using diluent.

\section{Acid degradation}

RVT patch formulation was transferred to $30.0 \mathrm{ml}$ of diluent to which $5.0 \mathrm{ml}$ of $0.1 \mathrm{~N} \mathrm{HCl}$ was added, heated to $80^{\circ} \mathrm{C}$ using a water bath for $6 \mathrm{~h}$ following which $5.0 \mathrm{ml}$ of $0.1 \mathrm{~N} \mathrm{NaOH}$ was added to the above solution to cease further degradation. The solution was further diluted with diluent to get a $1.0 \mu \mathrm{g} / \mathrm{ml}$ solution.

\section{Alkali degradation}

RVT patch formulation was transferred to $30.0 \mathrm{ml}$ of diluent to which $5.0 \mathrm{ml}$ of $0.01 \mathrm{~N} \mathrm{NaOH}$ was added, heated to $80^{\circ} \mathrm{C}$ using a water bath for 30 min following which $5.0 \mathrm{ml}$ of $0.01 \mathrm{~N} \mathrm{HCl}$ was added to the above solution to cease further degradation. The solution was further diluted with diluent to get a $1.0 \mu \mathrm{g} / \mathrm{ml}$ solution.

\section{Peroxide degradation}

RVT patch formulation was transferred to $30.0 \mathrm{ml}$ of diluent to which $5.0 \mathrm{ml}$ of $30 \%$ hydrogen peroxide was added and kept on bench top for $24 \mathrm{~h}$. This solution was further diluted with diluent to get a $1.0 \mu \mathrm{g} / \mathrm{ml}$ solution. Similarly, degradation studies were carried out for blank and placebo samples.

\section{Linearity}

$0.1,0.2,0.4,0.6,0.8,1.0,1.2,1.4,1.6,1.8$ and $2.0 \mu \mathrm{g} / \mathrm{ml}$ solutions were prepared from stock solution $(10.0 \mu \mathrm{g} / \mathrm{ml}$ concentration) and injected into HPLC and analysed in triplicates. The peak area was recorded and mean area, slope, Y-intercept, the correlation coefficient was calculated. A graph of peak area against concentration was plotted.

\section{Precision}

\section{System precision}

The standard solution was injected as six replicates. Peak area and $t_{R}$ were recorded, and mean and \%RSD were calculated.

\section{Method precision}

Six independent formulation samples were prepared and injected into HPLC. From the chromatograms, assay $(\%)$, mean assay and $\%$ RSD were calculated.

\section{Intermediate precision}

Six independent formulation samples were analysed on different days using a different instrument. From the chromatograms, assay (\%), mean assay and \%RSD were calculated and compared with the one obtained from the previous one.

\section{Content uniformity}

Ten independent formulation samples were prepared and assay (\%), mean and \%RSD of assay were calculated.

\section{Accuracy (Recovery)}

$1 \mathrm{ml}$ of $5.0 \mathrm{mg} / \mathrm{ml}, 10.0 \mathrm{mg} / \mathrm{ml}$ and $15.0 \mathrm{mg} / \mathrm{ml}$ of RVT stock solution was added into separate volumetric flasks containing $1 \mathrm{~cm}^{2}$ of RVT placebo patch and diluted with diluent to get $0.5 \mu \mathrm{g} / \mathrm{ml}(50 \%), 1.0 \mu \mathrm{g} / \mathrm{ml}$ $(100 \%)$ and $1.5 \mu \mathrm{g} / \mathrm{ml}(150 \%)$ concentration. Sample solutions were injected as triplicates. From the amount added and amount detected, $\%$ recovery was calculated.

$$
\text { Recovery }(\%)=\frac{\text { Amount recovered }}{\text { Amount added }} \times 100
$$

\section{Stability in the analytical solution}

The standard solution was prepared and kept on bench top for $72 \mathrm{~h}$. Stability of standard solution was assessed by injecting the standard solution into HPLC at $0 \mathrm{~h}$, $24 \mathrm{~h}, 48 \mathrm{~h}$ and $72 \mathrm{~h}$.

\section{Filter equivalency}

The formulation samples $(1.0 \mu \mathrm{g} / \mathrm{ml}$ concentration $)$ were filtered by using $0.45 \mu$ nylon syringe filter and the $\%$ assay was compared against the sample solution obtained by centrifugation at $8000 \mathrm{~g}$ for $10 \mathrm{~min}$. 


\section{Robustness}

Robustness study was performed using design of experiments (DoE), $2^{4}$ full factorial design using Design-Expert ${ }^{\circledR} \quad$ (version 9.0.4.1, Stat-Ease, Inc. Minneapolis, MN). To assess the robustness of the developed method, following chromatographic conditions were deliberately changed $v i \%$, A-flow rate $1 \mathrm{ml} / \mathrm{min} \pm 10 \%$, B-wavelength $306 \pm 5 \% \mathrm{~nm}$, C-mobile phase $\%$ buffer $\pm 2 \%$ and D-column oven temperature $25 \pm 5 \%$. The experiments were performed at two levels which yielded 16 runs in total (Table 1). Statistical analysis of the model was performed using analysis of variance (ANOVA). Changes if any, on peak area, theoretical plate count, retention time $\left(t_{R}\right)$ and tailing factor were assessed.

\section{System suitability test}

System suitability parameters were tested to ensure that during each analysis, the analytical procedure gives accurate and precise results. Six replicates of a single standard were injected to assess system suitability and $\% \mathrm{RSD}$, tailing factor and theoretical plate count was determined.

\section{Limit of detection (LOD) and Limit of quantification (LOQ)}

LOD and LOQ were calculated using standard deviation (SD) of Y-intercepts of regression lines and the slope of the calibration curve as mentioned in ICH guidelines.

\begin{tabular}{|c|c|c|c|c|}
\hline \multicolumn{6}{|c|}{ Table 1: ${ }^{4}$ full factorial design for robustness testing. } \\
\hline $\begin{array}{c}\text { Run } \\
\text { No. }\end{array}$ & $\begin{array}{c}\text { A: Flow } \\
\text { Rate } \\
(\mathrm{ml} / \mathrm{min})\end{array}$ & $\begin{array}{c}\text { B: } \\
\text { Wavelength } \\
(\mathbf{n m})\end{array}$ & $\begin{array}{c}\text { C: Mobile } \\
\text { phase } \\
\text { (\%Buffer) }\end{array}$ & $\begin{array}{c}\text { D: Column } \\
\text { oven } \\
\text { Temperature } \\
\text { ('C) }\end{array}$ \\
\hline 1 & -1 & 1 & 1 & -1 \\
\hline 2 & -1 & 1 & -1 & 1 \\
\hline 3 & 1 & -1 & -1 & 1 \\
\hline 4 & -1 & -1 & 1 & -1 \\
\hline 5 & 1 & 1 & -1 & 1 \\
\hline 6 & 1 & 1 & -1 & -1 \\
\hline 7 & -1 & -1 & -1 & 1 \\
\hline 8 & -1 & 1 & 1 & 1 \\
\hline 9 & -1 & -1 & -1 & -1 \\
\hline 10 & -1 & -1 & 1 & 1 \\
\hline 11 & 1 & -1 & 1 & -1 \\
\hline 12 & 1 & 1 & 1 & 1 \\
\hline 13 & 1 & 1 & 1 & -1 \\
\hline 14 & 1 & -1 & 1 & 1 \\
\hline 15 & 1 & -1 & -1 & -1 \\
\hline 16 & -1 & 1 & -1 & -1 \\
\hline
\end{tabular}

Application of the method for quantification of RVT in the formulation

The optimized transdermal patch was analyzed using the validated method. $1 \mathrm{~cm}^{2}$ of patch formulation was cut, extracted with diluent (50\% ACN in water) by sonicating for $15 \mathrm{~min}$ and diluted with diluent to get the same concentration as that of standard solution (i.e., $1.0 \mu \mathrm{g} / \mathrm{ml}$ ). The sample was then analyzed using HPLC in triplicates and \%assay was calculated.

\section{RESULTS}

The current work was aimed to develop a stability indicating HPLC method for the quantification of RVT in the developed formulations followed by its validation. The method was mainly concentrated on reducing the use of organic solvents keeping the mobile phase as simple as possible without the addition of buffer salts and $\mathrm{pH}$ adjustment. RVT was found to elute out at $6.96 \pm 0.08 \mathrm{~min}$. ICH Q2(R1) guidelines were followed for the validation of the developed method to check if the method was reliable for the analysis of RVT.

\section{Method optimization \\ Mobile phase}

Different mobile phases such as phosphate buffer $(0.025 \mathrm{M}) \mathrm{pH}$ 6.8, acetate buffer $(0.025 \mathrm{M}) \mathrm{pH} 4.5,0.1 \%$ OPA in water and $0.2 \%$ TFA with methanol/ACN as organic phase were tried. Phosphate buffer $\mathrm{pH} 6.8$ with methanol in different ratio were tried. At lower concentration of methanol, the peak due to RVT was broad and tailing factor was more than 2.0. Similarly, peaks with acetate buffer $\mathrm{pH} 4.5$ with varying ratio of methanol was broad and that with $0.1 \%$ OPA in water with varying ratio of methanol was comparatively better but tailing factor was more. $0.2 \%$ TFA with varying ratio of methanol/ACN gave a sharp peak without any interference due to placebo and diluent (Figure 1). In addition, a better theoretical plate count and less baseline noise were observed using ACN as the organic phase when compared to methanol. 25\% of organic ratio was found to give an optimum peak shape of RVT. Based on the results, 0.2\% TFA and ACN (75:25\% v/v) was finalized as the optimized mobile phase for the estimation of RVT in transdermal patches (Figure 2).

\section{Effect of column}

When $\mathrm{C}_{4}$ column was tried, a satisfactory peak shape was not obtained. $\mathrm{C}_{18}$ column showed a good peak shape with lesser retention time. $\mathrm{C}_{18}$ column with Kinetex (Phenomenex) chemistry showed better peak 


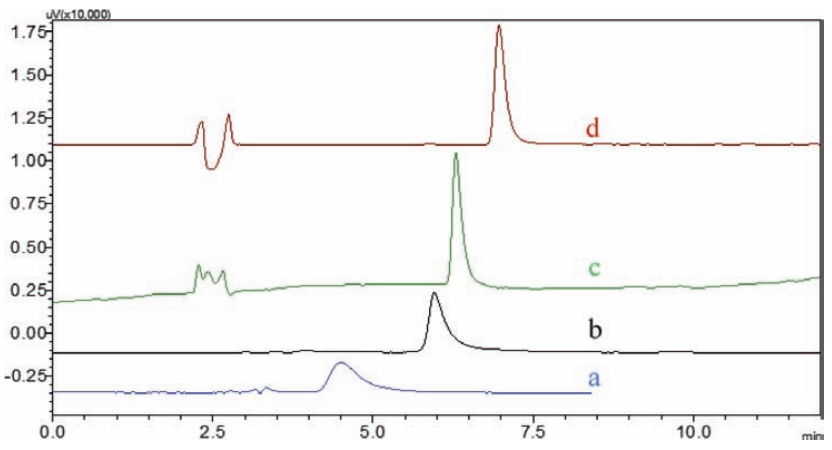

Figure 1: Chromatograms showing effect of different mobile phases on RVT peak a-pH 6.8 phosphate buffer $(0.025 \mathrm{M})$ : methanol $(50: 50 \% \mathrm{v} / \mathrm{v}), \mathrm{b}-\mathrm{pH} 4.5$ acetate buffer $(0.025 \mathrm{M})$ : methanol $(50: 50 \% \mathrm{v} / \mathrm{v}), \mathrm{c}-0.1 \%$ OPA : methanol $(70: 30 \% \mathrm{v} / \mathrm{v})$ and $d-0.2 \%$ TFA : ACN $(75: 25 \% \mathrm{v} / \mathrm{v})$.

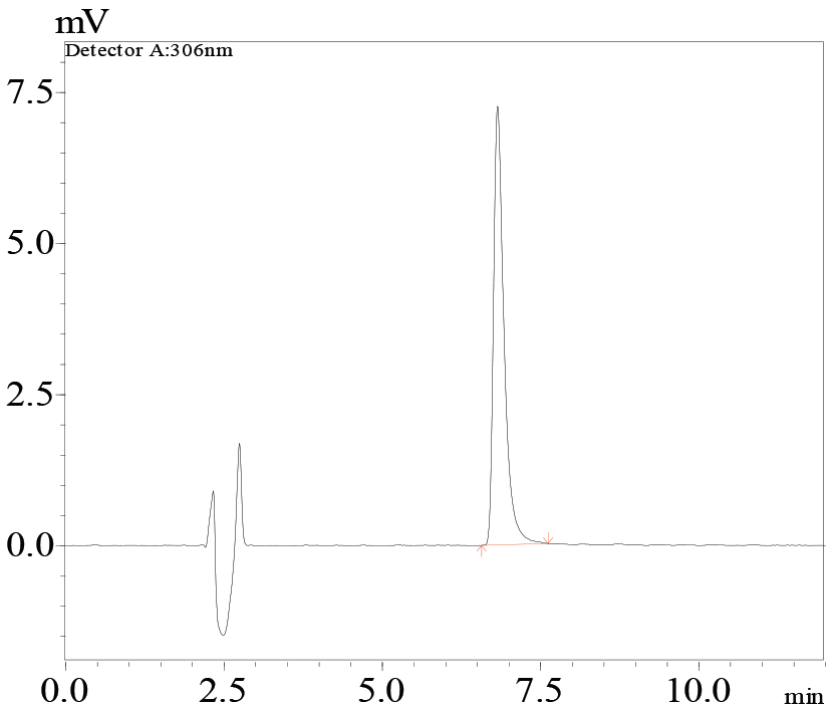

Figure 2: Chromatogram showing RVT peak at optimized chromatographic conditions.

shape and peak separation when compared to that with Luna (Phenomenex) chemistry.

\section{Effect of flow rate}

The flow rate did not show any major impact on RVT peak shape when flow was changed from $1 \mathrm{ml} / \mathrm{min}$ to $1.2 \mathrm{ml} / \mathrm{min}$. Hence flow rate was kept at $1 \mathrm{ml} / \mathrm{min}$.

\section{Column oven temperature}

Column oven temperature did not show any major impact on peak shape. There was very slight change in peak shape when temperature was changed from $25^{\circ}$ to $40^{\circ}$. Hence, column oven temperature was kept at $25^{\circ}$ as higher temperature may reduce the life of the column.
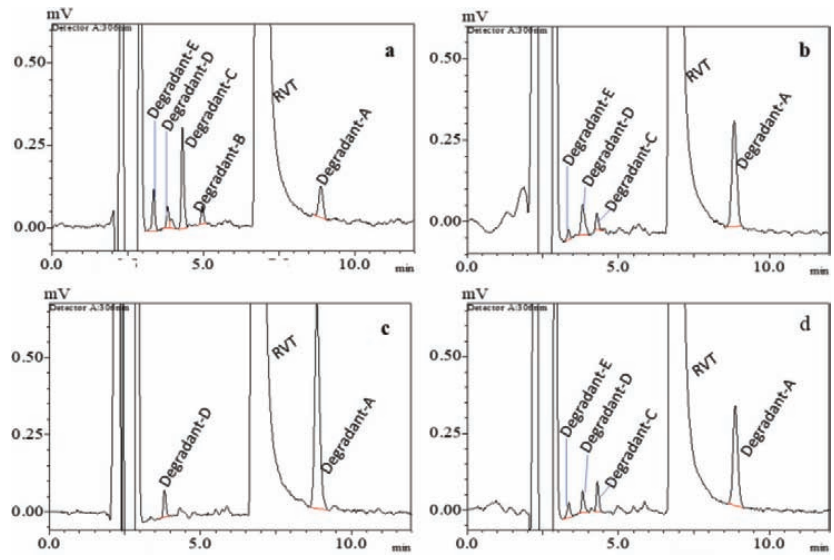

Figure 3: Chromatograms showing RVT and degradants peaks a-Acid degradation, b-Alkali degradation, c- Peroxide degradation and d-Photolytic degradation.

\begin{tabular}{|c|c|c|}
\hline Stress conditions & Drug assay (\%) & $\begin{array}{l}\text { Degradation } \\
\text { (\%) }\end{array}$ \\
\hline $0.1 \mathrm{~N} \mathrm{HCl}, 80^{\circ}, 6 \mathrm{~h}$ & $96.85 \pm 0.53$ & $3.12 \pm 0.83$ \\
\hline $0.01 \mathrm{~N} \mathrm{NaOH}, 80^{\circ}, 30 \mathrm{~min}$ & $96.02 \pm 0.49$ & $3.96 \pm 0.68$ \\
\hline $\begin{array}{l}\mathrm{H}_{2} \mathrm{O}_{2} 30 \% \text {, room } \\
\text { temperature, } 24 \mathrm{~h}\end{array}$ & $95.66 \pm 0.35$ & $4.28 \pm 0.59$ \\
\hline Water, $80^{\circ}, 6 \mathrm{~h}$ & $99.83 \pm 0.23$ & \\
\hline $\begin{array}{l}\text { Exposed to sunlight for } \\
\qquad 24 \mathrm{~h}\end{array}$ & $96.94 \pm 0.34$ & $2.98 \pm 0.46$ \\
\hline $105^{\circ}$ for $24 \mathrm{~h}$ & $99.98 \pm 0.42$ & \\
\hline
\end{tabular}

\section{Force degradation study}

The degradation peaks were determined by injecting stressed sample along with stressed placebo and unstressed sample into the HPLC system. No degradant showed absorbance at same $t_{R}$ as that of RVT (Figure 3 ). RVT peak was found to be spectrally pure as observed on PDA detector in HPLC (Figure 4 and 5). The results of force degradation are presented in Table 2.

\section{Method validation}

Interference from solvent, placebo and product degradants (force degradation) was evaluated at the $t_{R}$ of RVT main peak (Figure 6). The RVT peak was spectrally pure at a single wavelength $(306 \mathrm{~nm})$ and the whole range of UV wavelength as shown in the PDA detector (Figure 4 and 5). The method was found to be linear in the range of $0.1 \mu \mathrm{g} / \mathrm{ml}$ to $2.0 \mu \mathrm{g} / \mathrm{ml}$ concentration with correlation coefficient 0.9998 . The suitability of the system for the analysis of RVT was confirmed by the system precision test. $\%$ RSD of peak area and $t_{R}$ was found to be 0.58 and 0.19 respectively. The accuracy and precision of the proposed method were established, the results of which are presented in Table 3 and 4 . The 

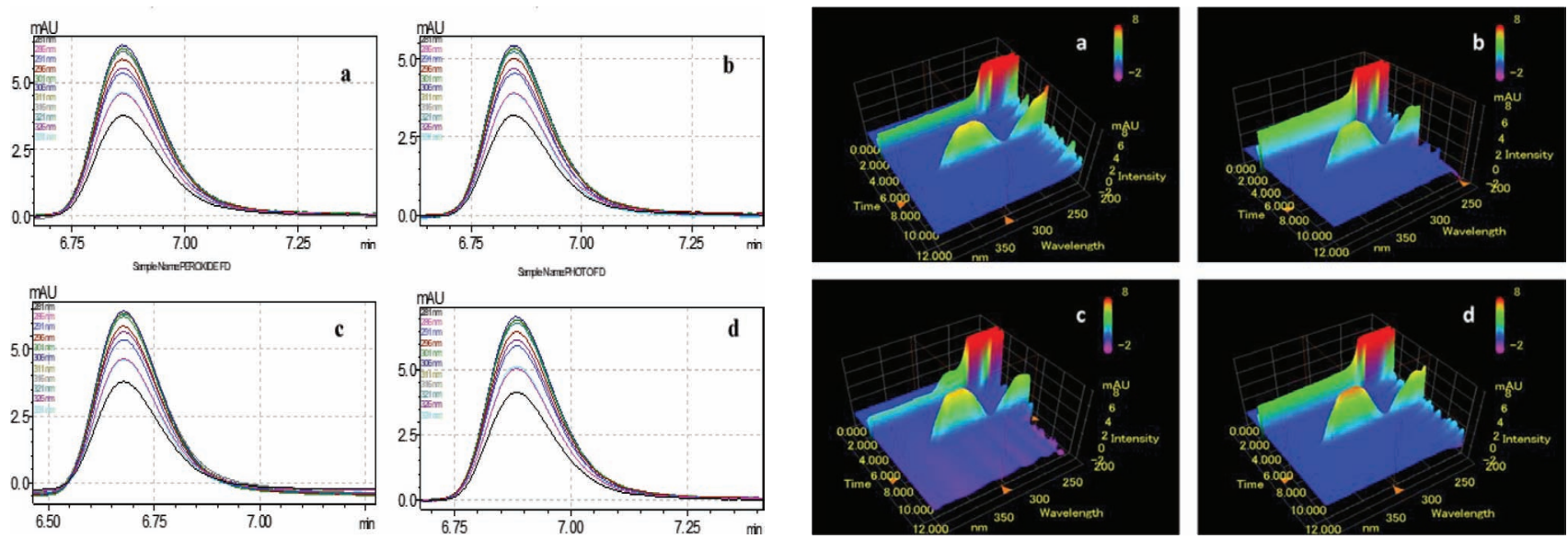

Figure 4: Graphs showing absorbance from 285-335 nm a-Acid degradation, b-Alkali degradation, c- Peroxide degradation and d-Photolytic degradation.

Figure 5: 3D chromatograms showing no interference at $t_{B}$ of RVT. A-Acid degradation, b-Alkali degradation, c- Peroxide degradation and d-Photolytic degradation.

\begin{tabular}{|c|c|c|c|}
\hline \multicolumn{2}{|r|}{ Parameters } & \multirow{2}{*}{$\begin{array}{c}\begin{array}{c}\text { Acceptance } \\
\text { criteria }\end{array} \\
<2.0 \\
>2000 \\
<2.0\end{array}$} & \multirow{2}{*}{$\begin{array}{c}\text { Observed } \\
0.58 \\
7595 \\
1.68\end{array}$} \\
\hline $\begin{array}{l}\text { System } \\
\text { suitability }\end{array}$ & $\begin{array}{l}\text { \%RSD of six replicate standard } \\
\text { Theoretical plate count } \\
\text { Tailing factor }\end{array}$ & & \\
\hline $\begin{array}{l}\text { Linearity } \\
\text { Linear regression data }\end{array}$ & $\begin{array}{l}\text { Linearity }(\mu \mathrm{g} / \mathrm{ml})(n=3) \\
\qquad R^{2}\end{array}$ & $>0.9990$ & $\begin{array}{l}0.1-2.0 \\
y=86160 x-925.47 \\
0.9998\end{array}$ \\
\hline Precision & $\begin{array}{l}\text { \%RSD of the peak area of six independent formulation sample } \\
\text { \%RSD of pooled formulation sample analyzed in the different } \\
\text { instrument on a different day }\end{array}$ & $\begin{array}{l}<2.0 \\
<2.0\end{array}$ & $\begin{array}{l}0.43 \\
0.33\end{array}$ \\
\hline Accuracy & \% Recovery & 95 to105 & 100.16 to 101.73 \\
\hline Content uniformity & $\%$ RSD of the peak area of ten independent formulation sample & $<6.0$ & 1.68 \\
\hline Filter equivalency & $\%$ Assay difference of filtered and centrifuged sample & $<2.0$ & 0.35 \\
\hline
\end{tabular}

\begin{tabular}{|c|c|c|c|c|c|}
\hline \multicolumn{2}{|c|}{$\begin{array}{c}\text { Spike level } \\
\text { (\%) }\end{array}$} & Average area(n=3) & \multicolumn{2}{|c|}{ Drugle 4: Results of accuracy. } \\
\cline { 3 - 6 } & & Added & Recovered & Observed & Acceptance criteria \\
\cline { 2 - 6 } & & 5.0 & $4.92 \pm 0.12$ & $100.16 \pm 2.40$ & $95-105 \%$ \\
100 & $42669 \pm 1024.49$ & 10.0 & $9.94 \pm 0.145$ & $100.74 \pm 1.47$ & \\
150 & $135835 \pm 1253.30$ & 15.0 & $15.56 \pm 0.21$ & $101.73 \pm 1.39$ & \\
\hline
\end{tabular}

standard solution was found to be stable up to. up to $72 \mathrm{~h}$ with inter day \% RSD of 1.97 . LOD was found to be $1.89 \mathrm{ng} / \mathrm{ml}$ and LOQ $5.74 \mathrm{ng} / \mathrm{ml}$.

The simultaneous effect of flow rate, wavelength, column oven, mobile phase composition (\% buffer) and temperature on peak area, retention time, tailing factor and plate count was assessed by using $2^{4}$ full factorial design. Pareto charts and perturbation plots were used to study the effects of these variables. The quantitative value of the effects was evaluated by the coefficient of the terms of the equation. The half-normal plot was used to identify the significant factors affecting each of the responses. The significant terms were subjected to ANOVA test to obtain the $P$ value ( $P<0.05$ was considered significant) and equation for each of the responses (Table 5). From the results of Pareto charts and perturbation plots, it was observed that as the flow rate decreases, peak area was found to significantly increase (Figure 7 and 8) and flow rate was found to have a negative effect on $t_{R}$ and plate count. \% buffer was 

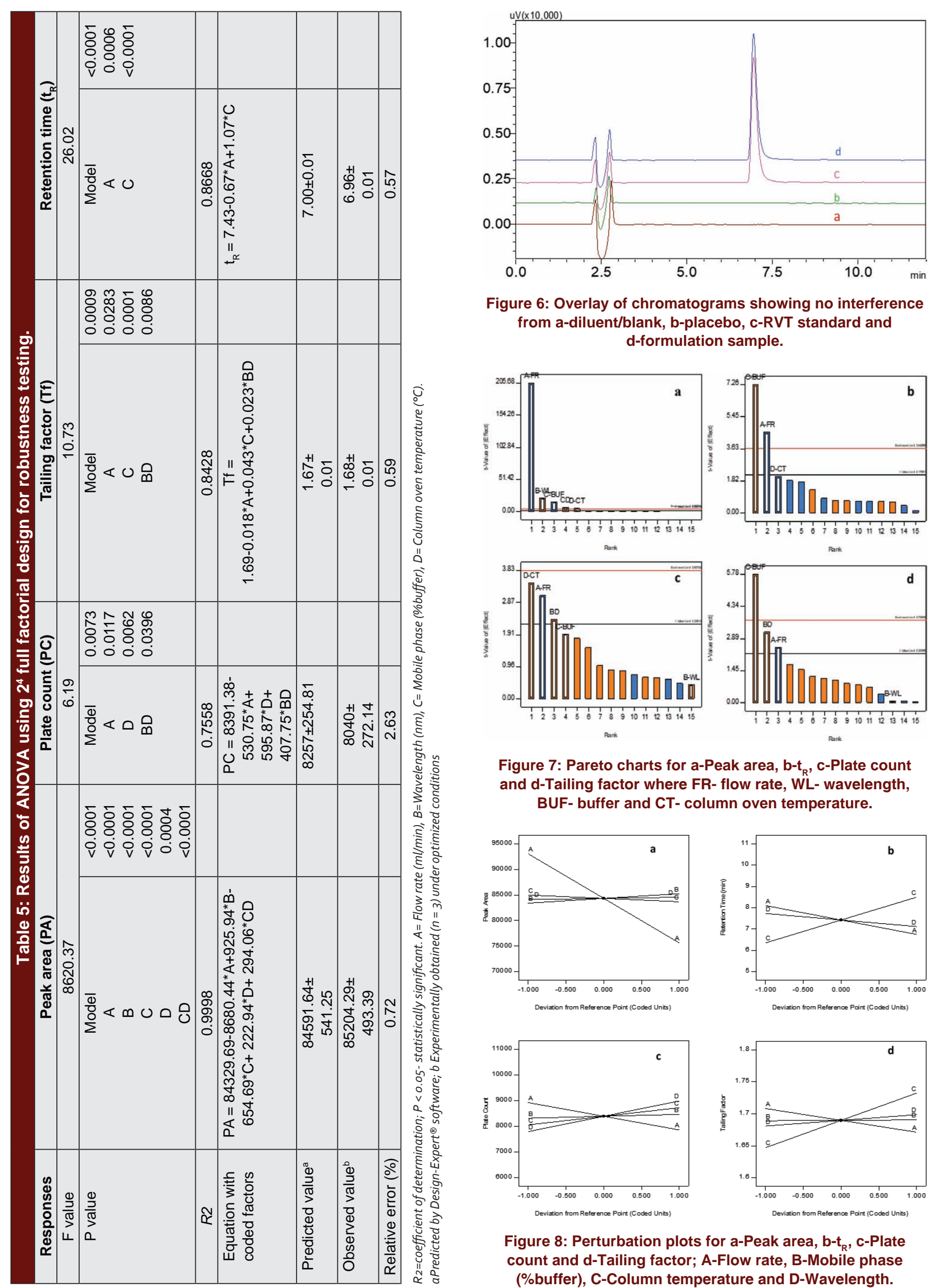

Figure 6: Overlay of chromatograms showing no interference from a-diluent/blank, b-placebo, c-RVT standard and d-formulation sample.
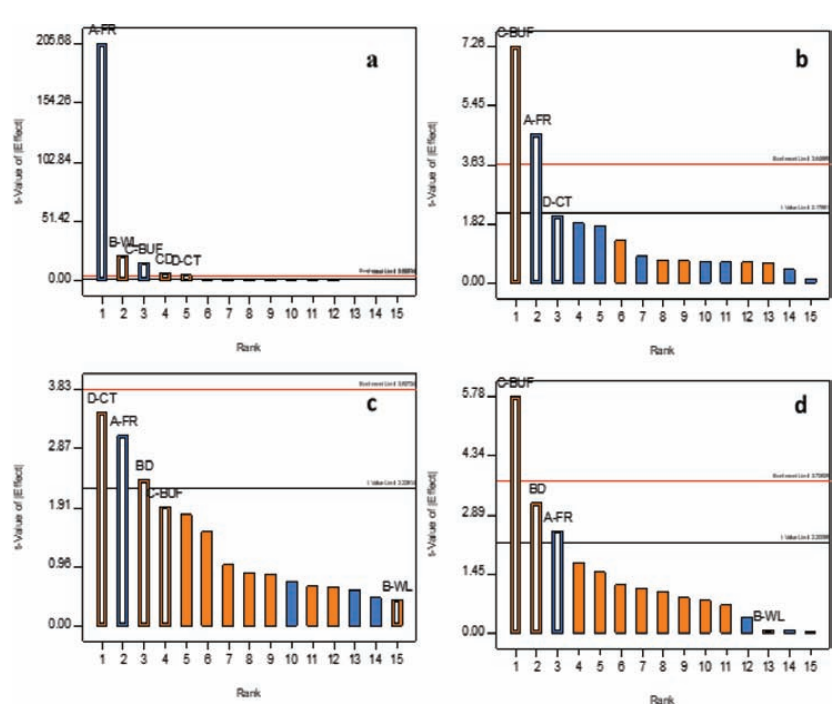

Figure 7: Pareto charts for a-Peak area, b-t $\mathrm{t}_{\mathrm{B}}$ c-Plate count and d-Tailing factor where FR- flow rate, WL- wavelength, BUF- buffer and CT- column oven temperature.
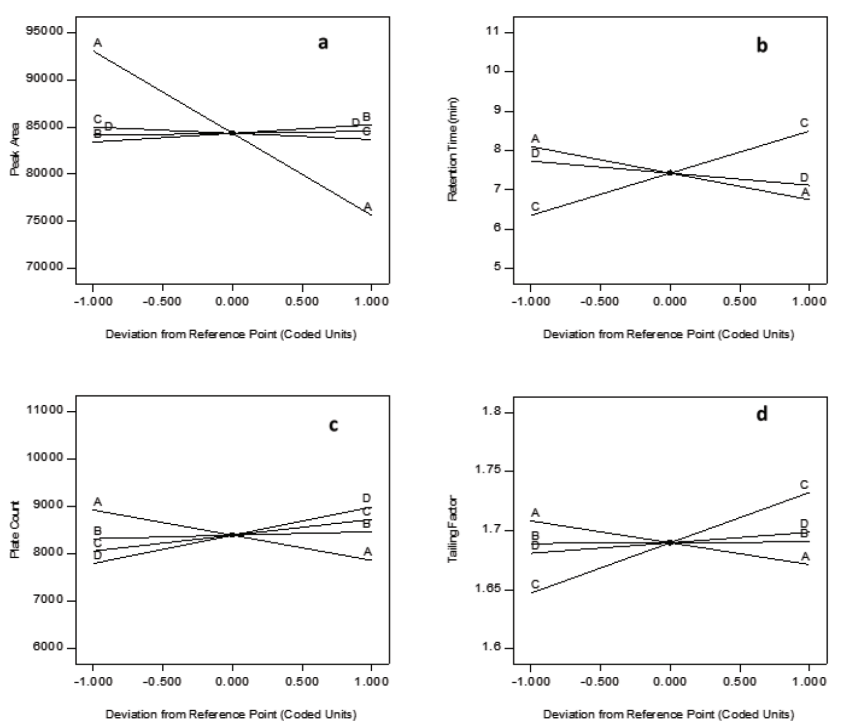

Figure 8: Perturbation plots for a-Peak area, $b-t_{\mathrm{R}}$, $c$-Plate count and d-Tailing factor; A-Flow rate, B-Mobile phase (\%buffer), C-Column temperature and D-Wavelength. 
found to have a negative influence on peak area and was found to increase the retention time of RVT. Column oven temperature was found to significantly influence the plate count. The \%RSD of the responses obtained from each trial when compared with those obtained from the optimized method was found to be $<1$ which suggested that the method was a robust one. The solution suggested by the software consisting of flow rate $(1 \mathrm{ml} / \mathrm{min})$, column oven temperature $\left(25^{\circ} \mathrm{C}\right)$, mobile phase content ( $\%$ buffer) $(75 \%)$ and wavelength $(306 \mathrm{~nm})$ showed a desirability value of 0.723 . The analysis was performed using the software predicted solution and the responses were validated by calculating the percentage relative error between the experimental and predicted results. The $\%$ relative error was found to be $<5 \%$ for all the responses.

\section{DISCUSSION}

The current study was aimed to develop and validate a stability-indicating HPLC method for the estimation of RVT in the developed formulations. The method was mainly concentrated on reducing the use of organic solvents keeping the mobile phase as simple as possible without the addition of buffer salts and $\mathrm{pH}$ adjustment and to reduce the run time. The developed method was validated as per ICH Q2(R1) guidelines to check if the method was reliable for the analysis of RVT.

\section{Method optimisation}

\section{Effect of mobile phase}

As the pKa of RVT is 8.49 (www.drugbank.ca), to avoid peak splitting, the $\mathrm{pH}$ of the mobile phase was kept at $8.49 \pm 2.0$. Lower $\mathrm{pH}$ was preferred as silanol activity will be less at lower $\mathrm{pH}$ (from $\mathrm{pH} 2.0$ to 6.0). ${ }^{24}$ Initially, trials were taken using methanol as the organic phase as it is cost-effective as compared to ACN. $\mathrm{pH}$ 6.8 phosphate buffer with methanol in different ratio were tried, broad peak and higher tailing factor was observed at lower organic composition. Organic solvent in the mobile phase was raised till 70\% v/v to obtain an appropriate peak shape. However, as our intention was to use lower organic content in mobile phase, this composition was not preferred. Trials with $\mathrm{pH} 4.5$ acetate buffer as the aqueous phase showed a broad peak of RVT and tailing factor was not within the limits when lower organic ratio was used. In addition, baseline disturbance was comparatively higher. With $0.1 \%$ OPA solution and varying ratio of methanol, a better peak shape at lower organic concentration was observed when compared to that with the previous trials; but baseline disturbance and peak tailing was seen. To avoid these, $0.2 \%$ TFA as aqueous phase was tried with varying ratio of methanol. In these trials, RVT peak was found to be satisfactory at lower methanol ratio. Nevertheless, at lower concentration of the analyte, peak shape was found to be inconsistent and slightly broad. Hence, ACN was tried in place of methanol as the organic phase. It was observed that RVT peak was sharper with higher plate count which may be attributed to the higher polarity of ACN when compared to methanol. Based on these observations, the method was finalised with $0.2 \%$ TFA and $\mathrm{ACN}$ as the mobile phase in the ratio of $75: 25 \% \mathrm{v} / \mathrm{v}$.

\section{Effect of column}

Different columns such as $\mathrm{C}_{4}$ and $\mathrm{C}_{18}$ were tried for the elution of RVT. The broader peak of RVT with tailing in $\mathrm{C}_{4}$ column even at higher organic ratio in the mobile phase may be due to the high affinity of RVT to the stationary phase. The RVT peak obtained using Phenomenex Kinetex $\mathrm{C}_{18}$ column was sharp with better plate-count as compared to that obtained with Phenomenex Luna $\mathrm{C}_{18}$ column. This may be due to the core-shell technology adopted in the Phenomenex Kinetex column which enhances the peak shape even at lower organic ratio (www.phenomenex.com/Kinetex/ CoreShellTechnology).

\section{Force degradation study}

The degradation peaks were determined by injecting stressed sample along with stressed placebo and unstressed sample into the HPLC system. The formulation sample of RVT was exposed to different stress conditions like thermal, light, acid, alkali and oxidative stresses to determine the specificity of RVT peak and peak purity of the same. The concentration of stressing agent and time of exposure to the stress was optimized to achieve detectable. amount of degradation. The study was performed to determine the peak purity of RVT and to assess other degradant peaks. RVT was found to be more susceptible to alkali degradation which was also reported in other literatures. ${ }^{16,25-26}$ The stability of RVT at lower $\mathrm{pH}$ may be because of the protection of hydroxy group by protonation at lower $\mathrm{pH}$ (around $\mathrm{pH}$ 1.2). ${ }^{27}$ The oxidative degradation of RVT was because of electrophilic attack of oxygen radical at the ionised phenoxy group to form phenoxy radical which will further lead to the formation of secondary degradant products. ${ }^{28}$ The UV rays in the sunlight causes isomerisation of RVT to cis-resveratrol and other degradants. ${ }^{29}$ The developed method was found to be specific to RVT which was confirmed by 
the absence of interference from the degradant peaks at the retention time of RVT (Figure 3).

\section{Method validation}

The proposed method was specific in the quantification of RVT in the formulation, as there was no interference from peaks of placebo, diluent and degradants at $t_{R}$ of RVT (Figure 4,5 and 6). The method was linear in the range of $0.1 \mu \mathrm{g} / \mathrm{ml}$ to $2.0 \mu \mathrm{g} / \mathrm{ml}$ which was evident from the correlation coefficient. System suitability, accuracy, precision test indicated that the method gives accurate and precise results while analysing RVT.

To analyse the robustness of the method, flow rate, wavelength, column oven temperature and mobile phase composition (\% buffer) were varied and their effect on peak area, plate count, tailing factor and retention time, was assessed by using $2^{4}$ full factorial design. The design helps in assessing the effect of the main factors as well as interaction effects on the responses. Pareto charts and perturbation plots were used to study the effects of the variables. The value of the coefficient of the terms of the equation generated by the software aids in predicting the effect quantitatively. The robustness of the method was confirmed from the $\%$ RSD of assay which was found to be $<1 \%$ when compared with the optimized method. The strength of the solution generated by the Design-Expert ${ }^{\circledR}$ software is given by the desirability value which ranges from 0 to 1 . The solution with a desirability value equal to or closer to 1.0 suggests that the corresponding method is highly robust and the most preferable one. A low $\%$ relative error $(<5 \%)$ indicated a strong agreement between the observed and predicted results thereby suggesting that the method may yield reproducible results for the analysis of RVT.

\section{Application of the method for quantification of RVT in the formulation}

The RP-HPLC method developed in the current study was applied to quantify the amount of RVT present in the transdermal patch. It was found that developed method was specific, as there was no interference due to blank peak, placebo peak or/and peak due to degradation of the formulation. The recovery of drug from the formulation components was challenging and this method showed a recovery which was well within the limit. The results suggest that the developed method may be used efficiently for analysing the amount of RVT in the transdermal patch.

\section{CONCLUSION}

The HPLC method developed was found to be simple, precise, sensitive and reproducible for the determination of RVT. The method was validated over the concentration range of $0.1-2.0 \mu \mathrm{g} / \mathrm{ml}$ and was found to offer good accuracy and precision for the quantification of the drug. The method was highly robust as a slight change in mobile phase composition and instrument parameters did not affect the results. With the help of DoE, the effect of chromatographic parameters was assessed on the peak area, theoretical plate count, retention time and tailing factor of RVT. LOD and LOQ established by this method were found to be lesser than the reported methods. In addition, the method proposed in this study was found to be highly specific for the detection of RVT in the presence of other formulation components. So far, as no literatures are available on stability indicating HPLC method for the quantification of RVT, our study will be advantageous for the quantitative analysis of RVT in pharmaceutical preparation, dietary supplements and bulk drug.

\section{ACKNOWLEDGEMENT}

Authors are thankful to Manipal College of Pharmaceutical Sciences, Manipal for providing facilities to carry out this research work.

\section{Funding}

This work was supported by the Science and Engineering Research Board, Dept. of Science and Technology, New Delhi, India (Ref. No. EMR/2016/007006).

\section{CONFLICT OF INTEREST}

The authors declare no conflict of interest.

\section{ABBREVIATIONS}

ACN: Acetonitrile; ANOVA: Analysis of variance; API: Active pharmaceutical ingredient; DoE: Design of experiments; GC-MS: Gas chromatography- Mass spectrometry detector; HCl: Hydrochloric acid; HPLC-MS: HPLC with mass spectrometry detector; ICH: International Conference On Harmonisation of Technical Requirements for Registration of Pharmaceuticals for Human Use; LOD: Limit of detection; LOQ: Limit of quantification; MNU-1: methyl-1-nitrosourea; $\mathbf{N a O H}$ : Sodium hydroxide; OPA: Ortho 
phosphoric acid; PDA: Photodiode array detector; RP-HPLC: Reversed-phase high performance liquid chromatography; RVT: Trans-resveratrol; RSD: Relative standard deviation; $\mathbf{R}_{r}$ : Retention time; TEA: Triethylamine; TFA: Trifluoroacetic acid; UV: Ultraviolet.

\section{REFERENCES}

1. Ndiaye M, Philippe C, Mukhtar $\mathrm{H}$, Ahmad N. The grape antioxidant resveratrol for skin disorders: promise, prospects, and challenges. Arch Biochem Biophys. 2011 Apr 15;508(2):164-70. doi: 10.1016/j.abb.2010.12.030, PMID 21215251.

2. Fiod Riccio BV, Fonseca-Santos B, Colerato Ferrari P, Chorilli M. Characteristics, biological properties and analytical methods of transresveratrol: a review [internet]. Crit Rev Anal Chem. 2020;50(4):339-58. doi: 10.1080/10408347.2019.1637242, PMID 31353930.

3. Bishayee A. Cancer prevention and treatment with resveratrol: from rodent studies to clinical trials. Cancer Prev Res (Phila). 2009 May 1;2(5):409-18. doi: 10.1158/1940-6207.CAPR-08-0160, PMID 19401532.

4. Sinha D, Sarkar N, Biswas J, Bishayee A. Resveratrol for breast cancer prevention and therapy: preclinical evidence and molecular mechanisms. Semin Cancer Biol. 2016 Oct;40-41:209-32. doi: 10.1016/j. semcancer.2015.11.001, PMID 26774195.

5. Athar M, Back JH, Tang X, Kim KH, Kopelovich L, Bickers DR, Kim AL. Resveratrol: a review of preclinical studies for human cancer prevention. Toxicol Appl Pharmacol. 2007 Nov 1;224(3):274-83. doi: 10.1016/j. taap.2006.12.025, PMID 17306316.

6. Berman AY, Motechin RA, Wiesenfeld MY, Holz MK. The therapeutic potential of resveratrol: a review of clinical trials. npj Precis Oncol. 2017 Dec 25;1(1):35. doi: 10.1038/s41698-017-0038-6, PMID 28989978.

7. Montes R, García-López M, Rodríguez I, Cela R. Mixed-mode solid-phase extraction followed by acetylation and gas chromatography mass spectrometry for the reliable determination of trans-resveratrol in wine samples. Anal Chim Acta. 2010 Jul 12;673(1):47-53. doi: 10.1016/j.aca.2010.05.021, PMID 20630177.

8. Vlase L, Kiss B, Leucuta SE, Gocan S. A rapid method for determination of resveratrol in wines by HPLC-MS. J Liq Chromatogr Relat Technol. 2009 Aug 17;32(14):2105-21. doi: 10.1080/10826070903126989.

9. de Souza Dias F, Silva MF, David JM. Determination of quercetin, gallic acid, resveratrol, catechin and malvidin in Brazilian wines elaborated in the vale do São Francisco using liquid-liquid extraction assisted by ultrasound and GC-MS. Food Anal Methods. 2013 Jun 21;6(3):963-8. doi: 10.1007/s12161012-9507-2.

10. Viñas P, Campillo N, Martínez-Castillo N, Hernández-Córdoba M. Solid-phase microextraction on-fiber derivatization for the analysis of some polyphenols in wine and grapes using gas chromatography-mass spectrometry. J Chromatogr A. 2009 Feb 27;1216(9):1279-84. doi: 10.1016/j.chroma.2008.12.058, PMID 19150539.

11. Goldberg DM, Yan J, Soleas GJ. Absorption of three wine-related polyphenols in three different matrices by healthy subjects. Clin Biochem. 2003 Feb;36(1):79-87. doi: 10.1016/s0009-9120(02)00397-1, PMID 12554065.

12. Meng $X$, Maliakal $P$, Lu H, Lee MJ, Yang CS. Urinary and plasma levels of resveratrol and quercetin in humans, mice, and rats after ingestion of pure compounds and grape juice. J Agric Food Chem. 2004 Feb 25;52(4):935-42. doi: 10.1021/jf030582e, PMID 14969553.

13. Almeida L, Vaz-da-Silva M, Falcão A, Soares E, Costa R, Loureiro Al, Fernandes-Lopes C, Rocha JF, Nunes T, Wright L, Soares-da-Silva P. Pharmacokinetic and safety profile of trans-resveratrol in a rising multiple- dose study in healthy volunteers. Mol Nutr Food Res. 2009 May;53;Suppl 1:S7-15. doi: 10.1002/mnfr.200800177, PMID 19194969.

14. Walle T, Hsieh F, DeLegge MH, Oatis JE, Walle UK. High absorption but very low bioavailability of oral resveratrol in humans. Drug Metab Dispos. 2004 Dec 24;32(12):1377-82. doi: 10.1124/dmd.104.000885, PMID 15333514.

15. Burkon A, Somoza V. Quantification of free and protein-boundtransresveratrol metabolites and identification oftrans-resveratrol-C/O-conjugated diglucuronides - two novel resveratrol metabolites in human plasma. Mol Nutr Food Res. 2008 May;52(5):549-57. doi: 10.1002/mnfr.200700290, PMID 18435437.

16. Nour V, Trandafir I, Muntean C. Ultraviolet irradiation of trans-resveratrol and HPLC determination of trans-resveratrol and cis-resveratrol in Romanian red wines. J Chromatogr Sci. 2012 Nov;50(10):920-7. doi: 10.1093/chromsci/ bms091, PMID 22689901.

17. Shah AA, Nayak Y. Development, optimisation and validation of RP-HPLC method for the quantification of resveratrol. Indian J Pharm Educ Res. 2019 Jul 1;53(3):S357-63.

18. Robinson K, Mock C, Liang D. Pre-formulation studies of resveratrol. Drug Dev Ind Pharm. 2015 Jan 1;41(9):1464-9. doi: 10.3109/03639045.2014.958753, PMID 25224342.

19. Yang NC, Lee $\mathrm{CH}$, Song TY. Evaluation of resveratrol oxidation in vitro and the crucial role of bicarbonate ions. Biosci Biotechnol Biochem. 2010;74(1):63-8. doi: 10.1271/bbb.90549, PMID 20057154.

20. Anisimova NYU, Kiselevsky MV, Sosnov AV, Sadovnikov SV, Stankov IN, Gakh AA. Trans-, cis- and dihydro-resveratrol: A comparative study. Chem Cent J. 2011 Dec 20;5(1):88. doi: 10.1186/1752-153X-5-88, PMID 22185600.

21. Gartziandia O, Lasa A, Pedraz JL, Miranda J, Portillo MP, Igartua M, Hernández RM. Preparation and characterization of resveratrol loaded pectin/alginate blend gastro-resistant microparticles. Molecules. $2018 \mathrm{Jul}$ 28;23(8):1886. doi: 10.3390/molecules23081886, PMID 30060551.

22. Singh G, Pai RS. A rapid reversed-phase HPLC method for analysis of trans -Resveratrol in PLGA nanoparticulate formulation. ISRN Chromatogr. 2014 Feb 16;2014:1-6. doi: 10.1155/2014/248635.

23. International Conference On Harmonisation of Technical Requirements for Registration of Pharmaceuticals for Human Use ICH Harmonised Tripartite. Guideline validation of analytical procedures: text and methodology. Vol. Q2. (p. R1) [internet]; 2005 [cited Jun 9 2019]. Available from: https://www.ich.org/ fileadmin/Public_Web_Site/ICH_Products/Guidelines/Quality/Q2_R1/Step4/ Q2_R1_Guideline.pdf.

24. Kirkland JJ, van Straten MA, Claessens HA. High pH mobile phase effects on silica-based reversed-phase high-performance liquid chromatographic columns. J Chromatogr A. 1995 Feb;691(1-2):3-19. doi: 10.1016/00219673(94)00631-ı.

25. Zupančič Š, Lavrič Z, Kristl J. Stability and solubility of trans-resveratrol are strongly influenced by $\mathrm{pH}$ and temperature. Eur J Pharm Biopharm. 2015 Jun 1;93:196-204. doi: 10.1016/j.ejpb.2015.04.002, PMID 25864442.

26. Long LH, Hoi A, Halliwell B. Instability of and generation of hydrogen peroxide by, phenolic compounds in cell culture media. Arch Biochem Biophys. 2010 Sep 1;501(1):162-9. doi: 10.1016/j.abb.2010.06.012, PMID 20558131.

27. Francioso A, Mastromarino P, Masci A, d'Erme M, Mosca L. Chemistry, stability and bioavailability of resveratrol. Med Chem. 2014 May;10(3):237-45. doi: 10.2174/15734064113096660053, PMID 24329932.

28. Graham N, Jiang CC, Li XZ, Jiang JQ, Ma J. The influence of $\mathrm{pH}$ on the degradation of phenol and chlorophenols by potassium ferrate. Chemosphere. 2004 Sep;56(10):949-56. doi: 10.1016/j.chemosphere.2004.04.060, PMID 15268961.

29. Camont L, Cottart CH, Rhayem Y, Nivet-Antoine V, Djelidi R, Collin F, Beaudeux JL, Bonnefont-Rousselot D. Simple spectrophotometric assessment of the trans-/cis-resveratrol ratio in aqueous solutions. Anal Chim Acta. 2009 Feb 16;634(1):121-8. doi: 10.1016/j.aca.2008.12.003, PMID 19154820. 


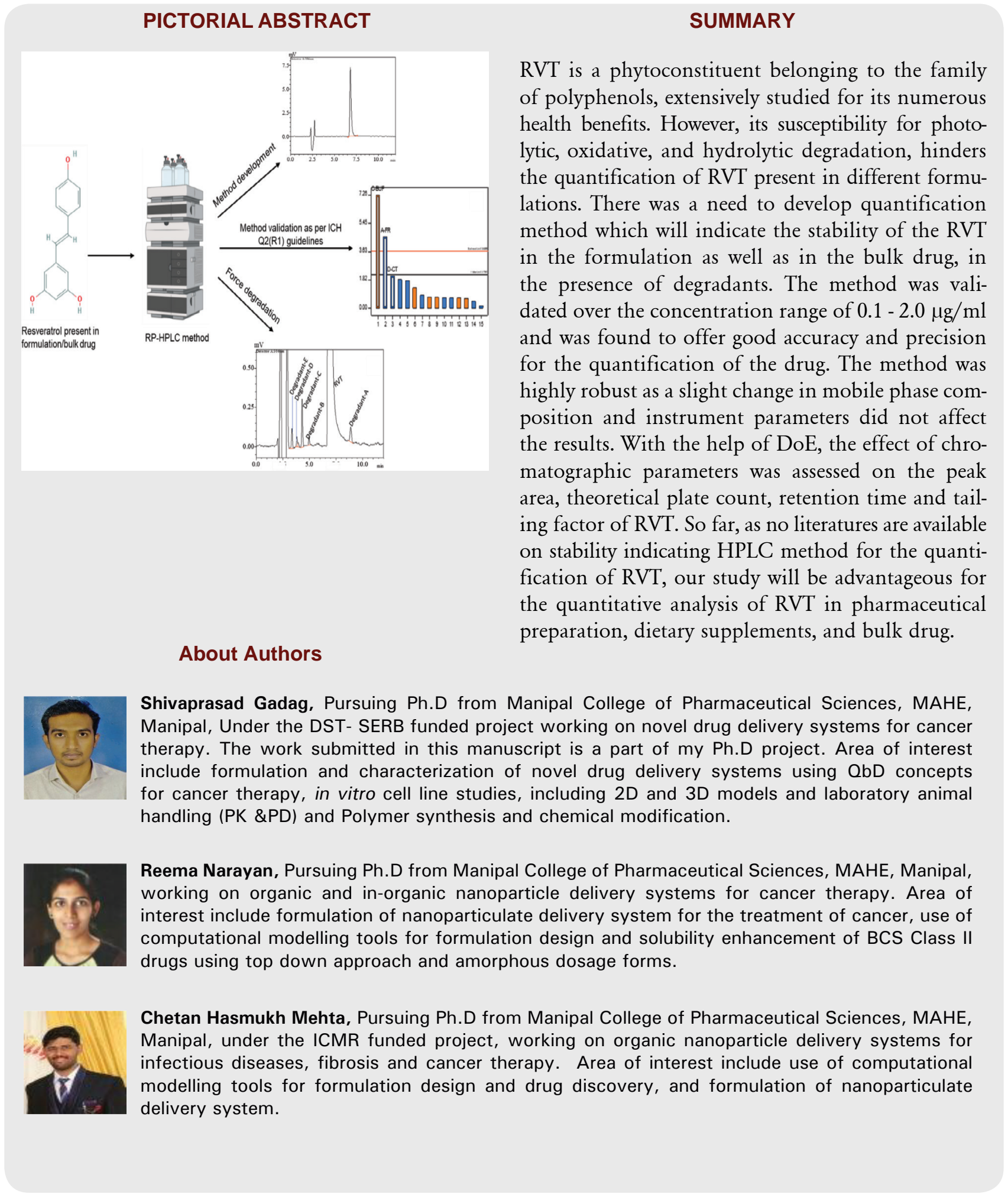




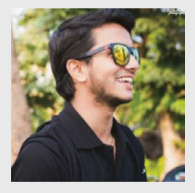

Akhil Suresh, Pursuing Ph.D from Manipal College of Pharmaceutical Sciences, MAHE, Manipal, working on different delivery systems for treatment of psychosis. Area of interest include pharmacokinetic studies in different animal model, PBPK modelling and simulation in drug development and use of computational modelling tools for formulation design and drug discovery.

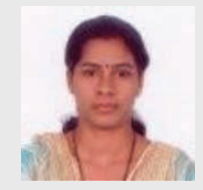

Usha Yogendra Nayak, Associate Professor, Department of Pharmaceutics, Manipal College of Pharmaceutical Sciences MAHE, Manipal. Mentor and PhD guide for the work mentioned in this manuscript. Having 13 years of experience in academia and research. Received research funding from DBT, DST-SERB, ICMR, AICTE-New Delhi, VGST-Govt. of Karnataka. Project consultant for LifeScient Inc., USA. Area of interest include development of organic and in-organic nanoparticles for different types of cancer, psychosis, and infectious diseases and use of computational modelling tools for formulation design and drug discovery.

Cite this article: Gadag S, Narayan R, Mehta CH, Suresh A, Nayak UY. Development and Validation of a Rapid and Sensitive Stability-indicating RP-HPLC Method for Resveratrol Quantification in Pharmaceutical Formulation. Indian $\mathrm{J}$ of Pharmaceutical Education and Research. 2021;55(3s):s825-s836. 